\title{
A Day in the Life of Person Who Has Had Type 1, "Juvenile Onset, Insulin Dependent" Diabetes Mellitus (T1DM) for 57 Years
}

\author{
Ken Kortas* \\ Executive Medical Science Liaison, General Medicine, US Business Unit, Diabetes Medical, Sanofi Pharma, USA \\ Email: ken.kortas@sanofi.com
}

How to cite this paper: Kortas, K. (2021) A Day in the Life of Person Who Has Had Type 1, "Juvenile Onset, Insulin Dependent" Diabetes Mellitus (T1DM) for 57 Years. Journal of Diabetes Mellitus, 11, 179-184. https://doi.org/10.4236/jdm.2021.115014

Received: September 21, 2021

Accepted: November 12, 2021

Published: November 15, 2021

Copyright $\odot 2021$ by author(s) and Scientific Research Publishing Inc. This work is licensed under the Creative Commons Attribution International License (CC BY 4.0).

http://creativecommons.org/licenses/by/4.0/

\begin{abstract}
How we manage T1DM has changed dramatically and significantly over the past 57 years. The information I have detailed below is my perspective on how my family and I monitored and treated my T1DM 57 years ago as we were taught by the amazing nursing staff at Resurrection Hospital. Great strides with T1DM have been made since starvation diets and with the discovery of insulin 100 years ago: the discovery of insulin at the Department of Physiology, University of Toronto, Canada, in 1921-22 was one of the most dramatic events in the history of therapeutics. Insulin's impact was so exciting and sensational because of the incredible effect it had on Type 1 patients with diabetes-truly a miracle of medicine in the 20th century. Frederick Banting and Charles Best won the Nobel Prize in 1922: "called one of the greatest achievements of modern medicine".
\end{abstract}

\section{Keywords}

Type 1 Diabetes Mellitus (T1DM), Continuous Glucose Monitor (CGM), Insulin, Clinitest ${ }^{\mathrm{TM}}$, Tes-Tape ${ }^{\mathrm{TM}}$

I am a 57-year-old person with T1DM. Needless to say, how we manage T1DM has changed significantly and markedly over the past 57 years. Discovery of insulin revolutionized the management of diabetes is appropriately acknowledged to be "one of the greatest achievements of modern medicine" [1]. Currently, we have continuous glucose monitoring (CGM) and glucose meters to check finger stick blood glucose to monitor blood sugars (BS). Both are very easy, convenient, and accurate means that provide us up to the minute BS readings ideal for insu-

*These views are my own and do not present any views of Sanofi. 
lin treatment adjustments. These allow us to control our BS within the desired range chosen for individual patients. For administering insulin, we now have many methods such as insulin syringes/pens, continuous subcutaneous insulin infusion (CSII) pumps, smart insulin pens, inhaled insulin, and insulin patches-and there's even a closed loop artificial pancreas (CSII + CGM).

Believe me, as difficult as diabetes management may seem or sound to many people with T1D or T2D today, it is a far cry from diabetes treatment and management over the last 50 years.

Now, I will relate the T1DM management procedures I was taught by the hospital staff at the time I was first diagnosed.

I will start by taking you through the typical things I did for my diabetes growing up with T1D back in the 1960s. The "finger stick" method for testing BS came out in the early 1980's - this was a godsend for us with diabetes! Prior to this if I wanted an actual blood sugar reading (which was done every 3 months prior to my doctor appointment) I had to go on a Saturday morning to the laboratory at Resurrection Hospital in Park Ridge, IL (about a 15-minute drive from my home) for a fasting BS testing. A week later, my BS level would be discussed with my doctor at the clinic and adjustment in my insulin regimen was recommended.

Back in the 1960s I routinely did urine sugar testing utilizing Clinitest ${ }^{\mathrm{TM}}$ (Miles Laboratories) tablets every morning, before meals and at bedtime. I urinated into a container and then placed 5 drops of urine and 10 drops of water into a test tube with a Clinitest ${ }^{\mathrm{TM}}$ tablet. I had to wait 60 seconds for it to turn color, then shake it and wait another 60 seconds. Then, I had to hold the test tube alongside a color comparison chart to see my urine sugar as follows: none (blue color), trace (green color), or $1+, 2+$ or $3+$ (different shades of tan to orange) indicating the amount of sugar in my urine specimen. (It was an exothermic reaction, so I had to be careful where I held the test tube!!) This is what I used at home during grade school for morning, before meal, and at bedtime urine sugar readings. Later Clinitest ${ }^{\mathrm{TM}}$ tablets were replaced by Tes-Tape ${ }^{\mathrm{TM}}$ (Eli Lilly and Company) [2] to make the testing much easier and more user friendly (for males!). Using easier Tes-Tape ${ }^{\mathrm{TM}}$, I put the strip into the stream of urine and then held the strip to the back of the Tes-Tape ${ }^{\mathrm{TM}}$ container to read the coloration and determine the negative or plus amount of sugar1. I continued to use Tes-Tape ${ }^{\mathrm{TM}}$ during my high school years starting in the late 1960s.

The most difficult issue with the urine glucose testing methods was usually for the morning urine sugar testing on awakening. I had to do a "double-void", which consisted of emptying my bladder completely as soon as I woke up in the morning, then drinking $2-8$ ounces of water and testing the second voided urine. This procedure supposedly provided a more accurate reading of urine sugar (and therefore relating to my BS) before my morning injection of insulin. (Let me tell you, it was sometimes difficult to hurriedly obtain a second voided urine specimen!!)

Timing was an issue with the daily morning ritual consisting of double-void 
urination to get an accurate reading (accurate was very questionable considering the kidney's glycemic threshold of sugar excretion!!), then, calculating the insulin dose based on my urine sugar amounts, injecting my insulin dose 30 45 minutes before eating breakfast (remember just regular insulin (RI) was available back then!!) and then walking to grade school or later going to the bus stop for high school. Obviously, it was quite a morning exercise I went through every school day as compared to present day. Today I use CGM or finger stick BS to get an immediate BS reading and I adjust my insulin dose based on carbohydrate counting just 5 - 10 minutes before I eat if my BS reading is within normal. Wow, how times have changed and improved for people with diabetes!!

Now, I will talk about the insulins used back in the 1960s. Regular (quick acting) insulin (RI) and NPH (intermediate acting insulin) became available in both U40 (40 units/ml) and U80 (80 units/ml). U500 (500 units/ml) was available but only through a special order through Eli Lilly Pharmaceutical, Elkhart, Indiana, USA). The glass syringes (yes glass which had to be sterilized) had both U40 (40 $\mathrm{U} / \mathrm{ml})$ and $\mathrm{U} 80(80 \mathrm{U} / \mathrm{ml})$ demarcation on the syringe. Therefore, you had to be very careful in making sure that you received the correct Insulin concentration from the drug store and then, when drawing up the insulin, that you were reading the correct concentration on the syringe (I used U40). The U100 insulin concentration as well as human insulin became available in the 1980s. The insulin that I utilized before recombinant DNA human insulin was a combination of $70 \%$ beef and $30 \%$ pork insulin (there was also pure beef or pure pork available).

I took a combination of Regular and NPH insulins. My procedure was to boil the glass syringe, plunger and 26-gauge needle in boiling water in a small saucepan for 10 minutes, then remove the items from the boiling water and let cool. Then I inserted the glass plunger into the syringe and then firmly put on the needle. Then I injected air into the NPH vial, withdrew the needle, and injected air into the regular vial (the amount of air injected corresponded to the units of insulin that would be withdrawn). Then I withdrew my Regular Insulin. Then, I inserted the same syringe into the NPH vial after I gently rotated the NPH vial for 20 rotations between my palms (you must mix well). You must remember that NPH is a suspension, and this is extremely important even now with any insulin suspension [3] [4] and withdrew out the correct units of NPH. You then must inject immediately after drawing up the insulins. I had to do it in this order because I never wanted to mix the cloudy intermediate acting NPH into the clear faster acting RI vial. A nurse told my mother when I was first diagnosed that it was like doing dishes "you could mix some of the rinse water into the soapy water but not the reverse!" That's was how I remembered the correct way of drawing up the insulin!! I repeated the same procedure each day before dinner (after of course doing a double void specimen). After each injection I used a thin metal wire to clear out the needle and then a sharpening stone to sharpen the needle. Quite a time-consuming procedure before breakfast and dinner compared to what I do now!! 
I have been asked to talk to many diabetes support groups over the years and before doing so I asked the CDEs if their patients are adherent with their blood sugar monitoring. Many times, of course they say "No-not as good as they could be!" I then describe with the diabetes support group the way of testing urine sugars and boiling the syringe as I did, and the support group people are amazed at the way "it used to be" and then they realize what they have available now for monitoring and treating their own diabetes. CDEs tell me that the monitoring increases with their patients after the counseling!

In retrospect, it is apparent that ongoing evolving treatment paradigms based on important innovations regarding development and manufacturing of Insulins with physiologic profiles, insulin administration devices and methods of glycemic monitoring of diabetes since the discovery of insulin (Table 1) have improved quality of life over 57 years of my life with diabetes as well as that of other diabetics. I am also convinced that these innovations have extended life span of subjects with diabetes. Finally, I also realize that, despite the rather large difficulties in my early Type 1 diabetes management, with the help of my family, especially my mom, as well as my doctors, other healthcare professionals and friends, I have lived a remarkably "normal" life with no significant complications. Moreover, with advent of much more modern methods, I expect to do well in future. For this I am extremely grateful. Therefore, I feel it is necessary that I share my story so others with both Type 1 and Type 2 diabetes are encouraged to take heart and know that there is always a way to live a long and healthy life. Thankfully, I have.

Table 1. Chronology of important innovations with Insulins, insulin administering devices and methods and glycemic monitoring in diabetes since discovery of insulin.

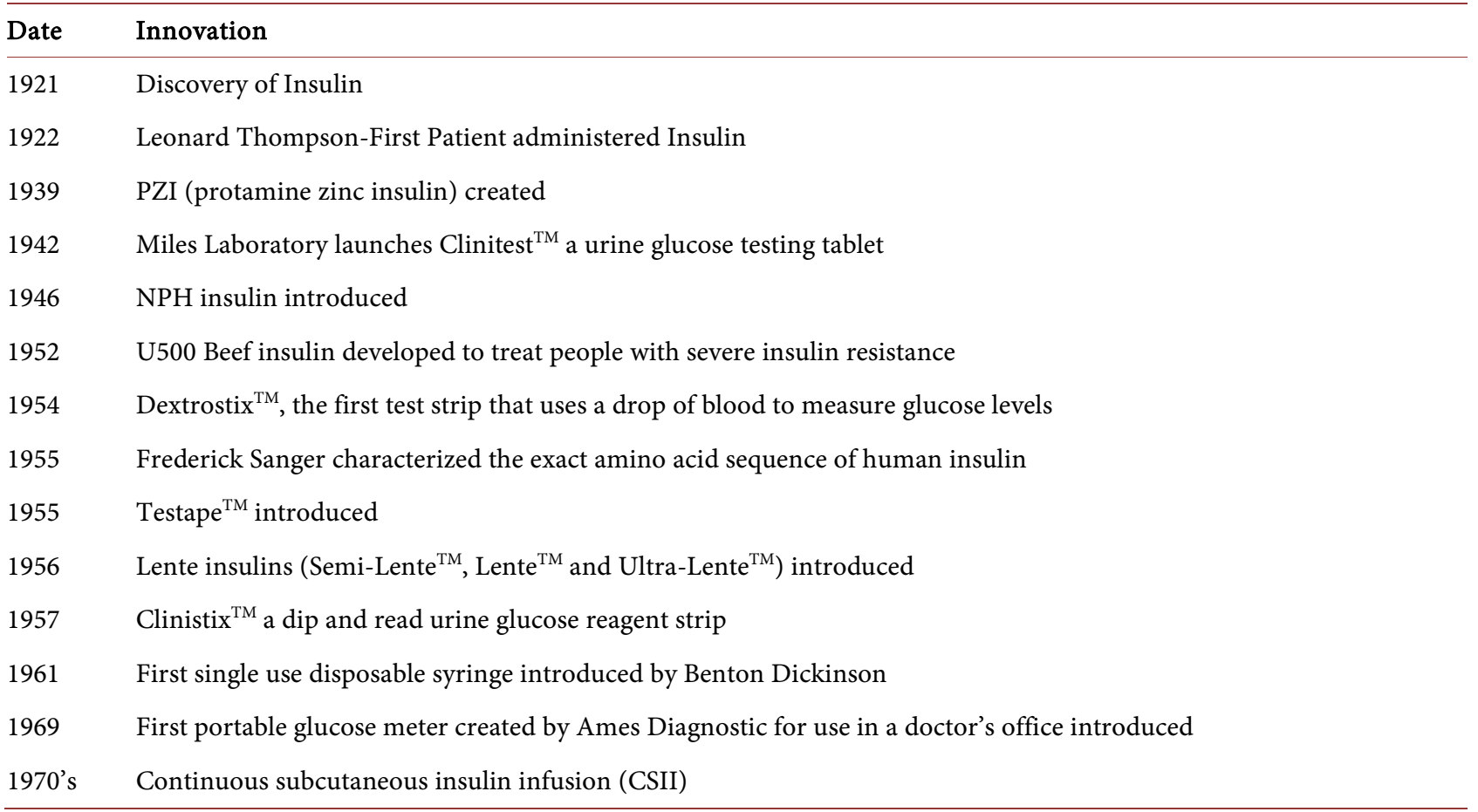




\section{Continued}

\begin{tabular}{|c|c|}
\hline 1972 & The first standardized U100 insulin is introduced \\
\hline 1973 & More highly purified Beef and Pork insulins introduced partially reduces local reactions \\
\hline 1977 & The first $\mathrm{HbA} 1 \mathrm{c}$ test is introduced into clinical laboratories \\
\hline 1980 & Basal-bolus concept and intensive insulin therapy introduced \\
\hline 1980 & Dextrometer ${ }^{\mathrm{TM}}$ first meter with a digital display and operated by a battery in UK \\
\hline 1980 & Glucochek ${ }^{\mathrm{TM}}$ by Lifescan became available in UK \\
\hline 1981 & Blood glucose monitors are ready for home use-the Ames Glucometer ${ }^{\mathrm{TM}}$ \\
\hline 1982 & FDA approves the first synthetic human insulin Eli Lilly and Company Humalin ${ }^{\mathrm{TM}}$ \\
\hline 1985 & Accucheck bG ${ }^{\mathrm{TM}}$ model 750 blood glucose monitor introduced \\
\hline 1992 & $\begin{array}{l}\text { Teddy Ryder at age } 5 \text { was one of the first people to received insulin in 1922, becomes the first person to live for } 70 \\
\text { years with T1DM. Teddy died of heart failure at age of } 76 \text { in } 1993\end{array}$ \\
\hline 1992 & OneTouch $\mathrm{II}^{\mathrm{TM}}$ by Lifescan-simple to operate, pre-calibrated and results in 45 seconds \\
\hline 1993 & $\begin{array}{l}\text { Results of the DCT show that people with T1DM can significantly lower their risks of complications by controlling } \\
\text { their blood sugars as close to normal as possible }\end{array}$ \\
\hline 1993 & Commercialization of the first instant glucose tablets \\
\hline 1994 & U500 human regular insulin (Reg-U500) approved by FDA \\
\hline 1996 & Insulin lispro (Humalog ${ }^{\mathrm{TM}}$ ) is the first rapid acting insulin introduced \\
\hline 1999 & First CGM approved \\
\hline 1999 & $\begin{array}{l}\text { Glucowatch Biographer }{ }^{\mathrm{TM}} \text { (Cygnus)-wristwatch with automatic, frequent monitoring with alarms for low and high } \\
\text { readings }\end{array}$ \\
\hline 2000 & First basal insulin analog approved \\
\hline 2006 & EDIC trial and "metabolic memory": tight glucose control for a period of time helps you live a longer, healthier life \\
\hline 2006 & Dexcom STS CGMS \\
\hline 2006 & Exubera $^{\mathrm{TM}}$ first inhaled insulin approve by FDA. Discontinued in 2007. \\
\hline 2008 & Freestyle Navigator CGM \\
\hline 2009 & Dexcom Seven Plus CGM \\
\hline 2009 & 2012 Dexcom G4 Platinum CGM \\
\hline $2013-2015$ & Longer acting basal insulin analogs approved \\
\hline 2014 & Inhaled Insulin Afrezza ${ }^{\mathrm{TM}}$ FDA approved \\
\hline 2015 & Dexcom G5 CGM \\
\hline 2016 & Freestyle Libre Pro Flash CGM \\
\hline 2016 & Medtronic MiniMed's iPro2 CGM \\
\hline 2017 & First FDA approved insulin smart-pen \\
\hline 2018 & Dexcom G6 CGM \\
\hline 2018 & Freestyle LIBRE 14 CGM (approved in Europe 2014) \\
\hline 2018 & Eversense implantable CGM-a smartphone-connected device, first approved in June 2018 \\
\hline 2020 & Freestyle LIBRE-2 CGM \\
\hline
\end{tabular}




\section{Acknowledgements}

My thanks to my good friend and colleague George S. Motto M.D., Board Certified in Endocrinology \& Metabolism, 1973 for his review as well as Dr. Udaya Kabadi for helpful comments.

\section{Conflicts of Interest}

The author declares no conflicts of interest regarding the publication of this paper.

\section{References}

[1] Majumdar, S.K. (2001) Glimpses of the History of Insulin. Bulletin of the Indian Institute of History of Medicine, XXXI, 57-70.

http://www.ccras.nic.in/sites/default/files/viewpdf/jimh/BIIHM_2001/57\%20to\%20 70.pdf

[2] 'Tes-Tape': Urine Sugar Test Tape. Wellcome Collection. https://wellcomecollection.org/works/bcacfjpy

[3] Lucidi, P., Porcellati, F., Andreoli, A.M., Carriero, I., Candeloro, P., Cioli, P., Bolli, G.B. and Fanelli, C.G. (2015) Pharmacokinetics and Pharmacodynamics of NPH Insulin in Type 1 Diabetes Mellitus: The Importance of Appropriate Resuspension before Subcutaneous Injection. Diabetes Care, 38, 2204-2210.

https://doi.org/10.2337/dc15-0801

[4] Jehle, P.M., Micheler, C., Jehle, D.R., Breitig, D. and Boehm, B.O. (1999) Inadequate Suspension of Neutral Protamine Hagendorn (NPH) Insulin in Pens. The Lancet, 354, 1604-1607. https://doi.org/10.1016/S0140-6736(98)12459-5 